\title{
Ventricular Tachyarrhythmia ECG Assessment
}

National Cancer Institute

\section{Source}

National Cancer Institute. Ventricular Tachyarrhythmia ECG Assessment. NCI Thesaurus. Code C111331.

An electrocardiographic assessment of the abnormally fast cardiac rhythms originating within the ventricles. 